\title{
What mergers can do for you
}

\author{
Anu Acharya \\ With careful due diligence, help from financiers and a keen eye, even small companies can grow through mergers \\ and acquisitions.
}

\begin{abstract}
The word 'merger' often is associated with a big company buying a smaller one or two large companies coming together. But it is not only large companies that can succeed through acquisitions-even startups can use mergers as an effective way to grow their businesses. As a small team leading the startup Ocimum Biosolutions, based in Hyderabad, India, a decade ago, my colleagues and I could have opted to grow the company internally. But early on, we decided to take the path of mergers and acquisitions (M\&As) to expand our company.

We had difficult choices to make as our business grew, and we learned invaluable lessons. Here, I share some of my experience and show how Ocimum evolved from a small company into a globally integrated genomics firm.
\end{abstract}

\section{Ocimum's long evolution}

Ocimum Biosolutions currently offers informatics solutions, wet lab genomic services and products for sample storage, processing and visualization of gene expression data, sequence data organization, small interfering RNA (siRNA) design, genome analysis, gene patterns, in silico gene optimization and customized biological databases. But a decade ago when Ocimum was just getting started, biological research had not yet comprehensively embraced 'omics-based approaches, and our business was based on a different model.

We started by collaborating with pharmaceutical and biotech research organizations, solving their challenges and increasing the productivity of their R\&D efforts through the application of our in-house informatics expertise. While doing this, we unearthed several places in the R\&D value chain that could be streamlined with informatics, but in our first few years, we grew organically. We maintained

Anu Acharya is CEO of Ocimum Biosolutions, Hyderabad, India.

e-mail:anu@ocimumbio.com a positive cash flow by licensing bioinformatics and enterprise software solutions like laboratory information management systems and by providing bioinformatics training.

Within a few years, we had built a thriving business with a steady pipeline. Money was coming in, and it would have been easy to be content with the direction of the company. However, Ocimum aspired to be more than a bioinformatics company-we wanted to be a 'lab next door' that could provide a researcher with services across the spectrum in a timely and cost-effective manner. To do this, we knew we would have to break out of our comfort zone and expand beyond the perceived limitations of our small team and startup company. We looked at our goals-a strong presence in the US, expansion of our portfolio of services to include biomarker discovery, and a customer base in Europe-and realized growth through acquiring assets seemed like a great way to build a large, scalable and sustainable company, so long as the pieces fit with our proprietary Research-as-a-Service (RaaS) business model. Ultimately, we achieved these goals through a combination of organic growth and three mergers (Table 1).

\section{When practicality conflicts with growth} Around 2005, closed microarray platforms and providers who lacked platform openness were the norm. Customers wanted customized and affordable microarray solutions, from study design to complete analysis with varying degrees of complexity, and we saw a need. Ocimum already had expertise in informatics solutions, and we thought we could acquire an open microarray technology platform, enabling us to access new customers and work more closely with existing ones.

Although we had a small lab in Indianapolis, we were headquartered in India, and an overseas acquisition seemed like a mammoth task to us. It did not at first seem practical; indeed,
CEOs of biotech startups often experience the same perception that their business aims are not possible to put into practice. However, a tenet of business is to seize an opportunity when it arises; in Ocimum's case, our first merger was almost handed to us and that helped convince our team we could do it. We had previously come close to signing a contract with MWG Biotech, of Ebersberg, Germany, to bring it on as a customer in 2004; but when the company began to struggle and approached us about a possible acquisition of their Genomic Diagnosis (GD) division, we decided to acquire the business.

\section{Instincts and due diligence}

Once we started thinking about a merger, we knew MWG's technology platform would help us, and so would its impressive list of clients in Europe and the US. This brings up an interesting point about acquisitions: due diligence.

In this case, we were familiar with the company because we had been in contract talks. But we used investment bankers and lawyers to conduct our due diligence, and also consulted our advisors and knowledgeable family members. Because the asset was being sold in an as-is condition with no warranties, and because their GD division had been shut down for six months before we acquired it, we needed to get a firm grip on its value, which we then stacked up against the risk. On one hand the merger had substantial issues - this was a business that had basically failed-but on the other hand, we saw that we had a chance to dramatically increase the size and capacity of Ocimum. The biggest challenge facing us was unhappy MWG customers. They had no idea what had happened to their projects as MWG faltered before our purchase, and that taught me a lesson: unhappy customers can be made happy if you engage them. The ones who did not communicate with us (though we tried) were lost forever. If the company you are buying has 
Table 1 The three mergers of Ocimum

\begin{tabular}{ll} 
Acquisition & MWG's Genomic Diagnosis business \\
\hline Year & 2005 \\
\hline Country & Germany \\
\hline Reason & $\begin{array}{l}\text { To leapfrog the technology development } \\
\text { cycle and access European customer base }\end{array}$
\end{tabular}

\begin{tabular}{ll} 
How & $\begin{array}{l}\text { Almost a customer of ours, this was a } \\
\text { serendipitous opportunity that we saw } \\
\text { instant value in acquiring }\end{array}$ \\
\hline Time frame & Six months
\end{tabular}

Time frame Six months

Diligence Short process, mostly legal

Success
Isogen's oligonucleotide business

2006

The Netherlands

To vertically integrate, provide a starting point for all molecular biology work and further our European presence

We knew the type of company and location, and we searched based on those criteria

Including search, almost 12 months. For acquisition alone, three months

Legal and financial

No

\section{Gene Logic's genomics business}

2007

US

To acquire a database of disease-focused biomarker discovery and toxicogenomic suites through dedicated microarray programs. These were difficult for competitors to replicate and fit well both strategically and geographically with Ocimum

A banker contacted us in July about Gene Logic's intent, and within days we had the process rolling

Three months from initial contact to signing a binding agreement. Six months from start to transaction's close

Business, legal and financial

Yes current customers, make sure you reach out to them at the earliest possible moment.

When the MWG acquisition closed, we went looking for another target company, this time to integrate vertically-we wanted a firm that produced oligonucleotides. We found a likely target in Germany, but talks did not progress much before falling apart because the founder was unsure (that's rather common), and he also had a health problem and that caused the deal to fall through. Another lesson learned: we had already made the announcement to our workforce that this deal was going ahead. Having to retract that announcement was a challenge in managing both internal communications and morale.

Around that time, the International Finance Corporation (the private equity arm of the World Bank) was looking to invest in Ocimum under the condition that we acquire a European company working in oligonucleotides. So we initiated the process of acquiring major assets of Isogen Life Sciences, based in Ijsselstein, The Netherlands. Due diligence was far more comprehensive here than with MWG's GD business. We went through a complete financial, business and legal review. To handle this, we charted the entire process through our internal team in addition to utilizing our usual bankers and lawyers.

Our third acquisition required perhaps the most effort regarding due diligence. Gene Logic, a company based in Maryland, had not only a database of disease-focused biomarker discovery and toxicogenomic suites it had built through dedicated microarray programs, but also a fledgling services division. The database was difficult to replicate for competitors, and when Gene Logic decided to sell their genomic assets to retain focus on their drug-repositioning efforts, we saw a perfect opportunity.
Besides the regular diligences of legal, finance and operations teams, we spent a fair amount of time with Gene Logic employees and talked to external consultants in hopes of designing an optimal integration strategy, which meant that I became more personally involved in the process. As CEO, I wanted to ensure that we did both a business diligence and an analysis on how this would impact our overall strategy as a company. This was the most stringent of all our merger-related diligences, but once complete, Gene Logic slipped into our business smoothly.

\section{The costs involved}

The acquisition of MWG's open microarray platform enabled Ocimum to provide a new degree of integration and flexibility to the genomics community, but nothing of value ever comes for free. However, we were able to finish the transaction without getting any private equity or venture money-we completed the deal with our internal funds and a small amount of bank debt. This meant the acquisition made an impact on our business without undue expense.

Apart from the acquisitions I have mentioned, the Ocimum management team has looked at other companies with cash on their books and more stable businesses. But those not only had higher acquisition costs but also appeared to be poorer fits with us. With MWG's GD business, we knew exactly what we were getting: access to Europe and a technology we would not have to extensively develop.

For our other two acquisitions, we had the added pressure of simultaneously raising a fresh round of funding to go along with closing the deal, which can be a Herculean task. It made those deals harder to pull off, but we were growing, had bigger needs and thus scouted larger targets.
You'll also need to consider another kind of cost, beyond purchase price, when contemplating a merger: running costs. You'll need to make sure you can contain running costs of adding the new acquisition by finding synergies and increasing revenues. You should focus on sales force synergies (if either company has a product or service), general and administrative savings and operational efficiencies that can be derived from a merger. Cutting these can help you keep all the benefits of the new acquisition but stunt the cost of running a company now made larger.

\section{Until the end}

M\&As are complicated to initiate, negotiate and sign. They involve a lot of planning and investigating, as well as a time commitment from founders and management-all for something that could potentially hurt your business if it does not go as foreseen.

Yet mergers have to be treated from the beginning like they are a reality, even if they are not finally completed. Still, it serves as a reminder that entrepreneurs need to take risks and step forward into the unknown sometimes. If it does not work out, have faith that another fork will appear in the road. It usually does, sooner or later.

It's a sad fact of business that not all mergers will be successful. You certainly plan for them to be-you'd never start down that path if you didn't-but there are things you will not know until the deal is closed. For example, Ocimum acquired Isogen in 2006 in part for its biomolecules division, which we planned to use to expand our European presence and sell oligonucleotides to research labs. The idea was to get a foot in the door and to sell other informatics and lab services, but we ran into trouble with integration due to cultural issues, cost 
overruns and intense competition that required a greater investment than we originally anticipated. Even so, this merger helped us kick-start our new diagnostics division, which we now pursue in India. Through it, we've developed an influenza virus $\mathrm{H} 1 \mathrm{~N} 1$ kit, a tuberculosis spoligotyping kit (based on polymerase chain reaction amplification of a highly polymorphic direct repeat locus in the Mycobacterium tuberculosis genome) and many more that are in the pipeline.

In each of the acquisitions we strived to retain some of the existing culture of the acquired company while also implementing a global culture that allowed us to function as one company. As part of our due diligence, we always checked if the target company had a culture similar to ours to begin with. In some cases, we made mistakes, and it turned out that the time we spent managing Isogen far outweighed the revenue and profit we saw from it, so we eventually decided to discontinue opera- tions in The Netherlands. That acquisition did not work out as planned.

But each acquisition was a learning experience, and by our third M\&A, the process was smoother. Acquiring Gene Logic came with considerable challenges. We had to determine operational efficiency and cost standardization while also integrating Gene Logic into our overall business model and diversifying and customizing their capabilities to make solutions affordable to organizations other than big pharmas and biotechs. Even so, integration was a success within a short span of time because of the lessons we learned in previous acquisitions. Gene Logic 2.0 is now very well positioned to carry forward the genomic legacy it had meticulously built since its founding in the late 1990s.

\section{Conclusions}

There is a final benefit to mergers: positive change. In our first acquisition, one of the benefits that we greatly underestimated was the buzz created by the MWG acquisition, which led to instant name recognition and customer access worldwide for Ocimum. We received a similar boost when we incorporated Gene Logic into our business; indeed, we retained Gene Logic's name to capitalize on the genomics goodwill associated with the brand.

Amalgamation of disparate entities-be it MWG, Isogen or Gene Logic-is possible only because of complementary competencies and customer bases. Ocimum has graduated from being a small bioinformatics company in India to being a leading, integrated, global, one-stop solution provider for genomics. The same path could have been a recipe for disaster in a different geography or a different business model, but for us the three acquisitions were exactly what we needed. Thus, acquisitions can prove to be a very effective business strategy. Can you afford to miss out on them? 